\title{
Proliferative effects of gamma-amino butyric acid on oral squamous cell carcinoma cells are associated with mitogen-activated protein kinase signaling pathways
}

\author{
JING MA $^{1^{*}}$, YAN ZHANG ${ }^{2,3 *}$, JUN WANG $^{2,3}$, TIANYU ZHAO ${ }^{2,4}$, PING JI ${ }^{2,4}$, \\ JINLIN SONG ${ }^{2,3}$, HONGMEI ZHANG ${ }^{2,4}$ and WENPING LUO ${ }^{2,4}$ \\ ${ }^{1}$ Laboratory Animal Center, Chongqing Medical University, Chongqing 400016; ${ }^{2}$ Stomatological Hospital of \\ Chongqing Medical University; ${ }^{3}$ Chongqing Key Laboratory of Oral Diseases and Biomedical Sciences; \\ ${ }^{4}$ Chongqing Municipal Key Laboratory of Oral Biomedical Engineering of Higher Education, Chongqing 401147, P.R. China
}

Received October 19, 2015; Accepted April 22, 2016

DOI: $10.3892 / \mathrm{ijmm} .2016 .2597$

\begin{abstract}
Gamma-aminobutyric acid (GABA), the major inhibitory neurotransmitter in the adult mammalian central nervous system, has been reported to play an important physiological role in peripheral non-neuronal tissues, such as tumors. However, whether deregulated GABA is associated with oral squamous cell carcinoma (OSCC) is currently unknown. In this study, we investigated the effects of GABA on the proliferation of the OSCC cell line, Tca8113. Immunohistochemical analyses were performed to examine the expression of GABA A type receptor pi subunit (GABRP) in human OSCC tissues, and reverse transcription polymerase chain reaction, immunofluorescence staining and western blot analysis were performed to examine the expression of GABRP in Tca8113 cells. The proliferative effects of GABA on Tca8113 cells were analyzed by CCK- 8 assay and flow cytometry. The activation status of mitogen-activated protein kinases (MAPKs) was examined by western blot analysis. GABRP expression was observed in the cytoplasm with a higher level in poorly differentiated OSCC tissues. The mRNA and protein expression levels of GABRP were detected in the Tca8113 cells. The addition of GABA and the GABA A type receptor agonist, Muscimol, promoted cell proliferation and inhibited cell apoptosis through the activation of the p38 MAPK and the inhibition of the JNK MAPK signaling pathways. These results imply a novel role of GABA in OSCC.
\end{abstract}

Correspondence to: Ms. Wenping Luo, Stomatological Hospital, Chongqing Medical University, 426 Songshi Bei Road, Yubei, Chongqing 401147, P.R. China

E-mail: lwplucky@163.com

*Contributed equally

Key words: gamma-amino butyric acid, oral squamous cell carcinoma, proliferation, apoptosis, mitogen-activated protein kinase

\section{Introduction}

Oral squamous cell carcinoma (OSCC) is one of the most common malignant tumors of the oral and maxillofacial region. Alcohol consumption, betel quid chewing and cigarette smoking are the main accepted etiologies of OSCC thus far (1). Despite advances in the main treatments of surgery and radiotherapy, there have been relatively low 5-year survival rates. The development of tumors is a complex developmental process involving multiple factors, steps and signaling pathways, including mitogen-activated protein kinase (MAPK), phosphatidylinositol 3-kinase (PI3K), Notch and signal transducer and activator of transcription 3 (Stat3) (2-5). Numerous genes have been shown to affect the development and progression of SCC, thus suggesting various potential approaches with which to prevent and treat SCC (6-8). This has evoked increasing interest in tumor biological treatment that is able to predict prognosis.

Gamma-aminobutyric acid (GABA) is a non-protein amino acid that acts as the major inhibitory neurotransmitter in the adult mammalian central nervous system (CNS) (9). GABA can inhibit excessive excitement in the CNS and has a calming effect on the brain, thus promoting relaxation and eliminate nervousness (10). In a previous study, it was reported that GABA abolished the negative responses to nicotine, which included the growth of pancreatic ductal adenocarcinoma xenografts in mice (11). Owing to these physiological functions, several functional foods have been manufactured. Natural GABA was first found in potatoes and is widely obtained in nature among microorganisms, plants and animals. A wide range of traditional foods contain GABA, such as gammalone, cheese, gabaron tea, green tea and shochu, in which GABA is safe and eco-friendly, there are also possibility other products containing GABA with health benefits. It has been suggested that GABA has a variety of physiological functions, and GABA is a type of functional food additive (12).

Moreover, it has been reported that GABA plays a role in central and peripheral tumors, in addition to serving as an inhibitory neurotransmitter through its receptor (13). According to their pharmacological characteristics, GABA receptors have been divided into 3 types, A, B and C. Among the 3 types of 
receptors, A type receptors have a variety of functions in a number of peripheral non-neuronal tissues, such as the small intestine, pancreas and liver, and have different functions with respect to specific cell types (14-17). A typical GABA A type receptor subunit, named pi (GABRP), was detected in several peripheral tissues. It has been proposed that GABRP may play an important role in GABA A type receptor functions in nonneuronal tissues, including cancer cell proliferation in gastric cancer through the MAPK signaling pathways, which are the best known regulators of mammalian cell proliferation (18).

In clinical pharmacology, GABA is used considerably in pharmaceutical agents to alleviate pain in cancer, acting upon receptors of GABA and GABA 'mimetics' (e.g., gabapentin); however, the safe use of GABA for patients with tongue cancer has not yet been established (19). To data, and to the best of our knowledge, no studies have examined the association between GABA expression and OSCC, which may prove to be of significance for an improved diagnosis and treatment.

To develop a promising method for the effective treatment and prognosis of OSCC, it is necessary to obtain a better understanding of the molecular mechanisms responsible for the development of this disease. In the present study, we investigated the expression of GABRP in OSCC using tongue pathological sections and Tca8113 cells. Furthermore, we examined whether the effects of GABA and GABA A type receptor on Tca8113 cell proliferation and apoptosis are mediated through the MAPK signaling pathways.

\section{Materials and methods}

Chemicals and antibodies. GABA, Muscimol (GABA A type receptor agonist) and S106 (GABA A type receptor antagonist) were obtained from Sigma-Aldrich (St. Louis, MO, USA). GABRP polyclonal antibody was from Abcam (Cambridge, MA, USA). Antibodies against MAPK were purchased from Cell Signaling Technology (Danvers, MA, USA). The Cell Counting Kit-8 (CCK-8) was obtained from Dojindo Molecular Technologies, Inc., Shanghai, China. Other drugs used were of reagent grade.

Tissue samples. From 2012 to 2014, we obtained 24 tongue cancer samples (12 well-differentiated ones and 12 poorly differentiated ones) and 12 fibroplasia samples. Tongue cancer samples were obtained by tumor resection, while the fibroplasia samples were obtained by biopsy. All the samples were obtained from the Department of Pathology of Chongqing Medicial University (Chongqing, China) after obtaining the approval of the Ethics Committee of the Medical Department of Chongqing Medicial University. All patients provided written and signed consent prior to donating their tissue samples for use in scientific research. According to the WHO standard (1971), the differentiation of the cancer cells was divided into high (well-differentiated), and medium and low (poorly differentiated) levels.

Immunohistochemical staining of GABRP. All pathological sections (4-6 $\mu \mathrm{m}$ ) were deparaffinized and rehydrated. Endogenous peroxidase activity was blocked by incubating the sections in $3 \%$ peroxide in methanol for $30 \mathrm{~min}$ at room temperature. Following 3 washes in PBS, non-specific binding was blocked in $10 \%$ normal rabbit serum in PBS for $1 \mathrm{~h}$ at room temperature followed by incubation with rabbit anti-GABAAR pi primary antibody $(1.2 \mu \mathrm{g} / \mathrm{ml}$, ab26055; Abcam) overnight at $4^{\circ} \mathrm{C}$. Following 3 washes in PBS, the sections were subsequently incubated with horseradish peroxidase-conjugated goat anti-rabbit IgG (sp-9001; Zhongshan Biotechnology, Beijing, China) for $40 \mathrm{~min}$ at room temperature. The secondary antibody was detected with 3,3'-diaminobenzidine solution (sp-9001; Zhongshan Biotechnology). For some sections, the primary antibody was replaced with normal rabbit IgG $(2 \mu \mathrm{g} / \mathrm{ml} \mathrm{IgG}$; Abcam) instead of anti-GABA primary antibody to serve as the negative controls.

Cell culture. The Tca 8113 cells were obtained from the Shanghai Institute of Biochemistry and Cell Biology (SIBCB; Shanghai, China) and cultured in RPMI-1640 medium (Gibco Life Technologies, Carlsbad, CA, USA) supplemented with $10 \%$ (v/v) fetal bovine serum at $37^{\circ} \mathrm{C}$ in a humidified atmosphere containing $5 \% \mathrm{CO}_{2}$. A subcultivation ratio of $1: 3$ is recommended.

The Tca8113 cells, plated in cell culture dishes, were randomly divided into different treatment groups when adhered to the bottom of the dishes. We then selected the time points of 24 and $48 \mathrm{~h}$ after treatment for analysis. The treatment groups were as follows: group 1, negative control without any treatment; groups 2-4, addition of various concentrations of GABA (1, 10 or $100 \mu \mathrm{M}$ ) in culture medium, respectively; groups 5-7, addition of various concentrations of Muscimol $(0.5,5$ or $50 \mu \mathrm{M})$ in culture medium, respectively; and groups 8-10, addition of various concentrations of $\mathrm{S} 106(0.5,5$ or $50 \mu \mathrm{M})$ for $30 \mathrm{~min}$ in advance and then re-treatment with the optimal concentration of GABA according to the results obtained from groups 2-4.

Reverse transcription polymerase chain reaction (RT-PCR). Total RNA was isolated from the Tca8113 cells after the addition of various concentration of GABA, Muscimol and S106 at 24 and $48 \mathrm{~h}$ using TRIzol reagent (Invitrogen Life Technologies, Carlsbad, CA, USA) according to the manufacturer's instructions. The primer sequences of GABRP were as follows: forward, 5'-ATGAGCTACAGCCTCTATTT GGC-3'; and reverse, 5'-ACCACCGAAATTGGGCCTG-3' and the amplicon size was $174 \mathrm{bp}$. The primer sequences of GAPDH were as follows: forward, 5'-AGCCATGTACGTA GCCATCC-3'; and reverse, 5'-CTCTCAGCTGTGGTGGT GAA-3' and the amplicon size was $373 \mathrm{bp}$. Total RNA $(2 \mu \mathrm{g})$ was reverse transcribed in $20 \mu \mathrm{l}$ of reaction mixture containing $4 \mu \mathrm{l} \mathrm{MgCl}_{2}, 25 \mathrm{mM} ; 2 \mu \mathrm{l}$ reverse transcription $10 \mathrm{X}$ buffer; $2 \mu \mathrm{ldNTP}$ mixture, $10 \mathrm{mM}$; $0.5 \mu \mathrm{l}$ recombinant $\mathrm{RNasin}^{\circledR}$ ribonuclease inhibitor, $15 \mathrm{U}$ AMV reverse transcriptase (high concentration), and $0.5 \mu \mathrm{g}$ random primers (A3500; Promega, Madison, WI, USA). PCR was performed in a total volume of $25 \mu \mathrm{l}$ containing $12.5 \mu \mathrm{l}$ GoTaq $^{\circledR}$ Green Master Mix (M7122; Promega), $0.5 \mu \mathrm{M}$ primers and $1 \mu \mathrm{l} \mathrm{cDNA}$ and was carried out over 25 cycles. The thermal cycling conditions were as follows: $94^{\circ} \mathrm{C}$ for $30 \mathrm{sec}, 59-61^{\circ} \mathrm{C}$ for $30 \mathrm{sec}$, and $72^{\circ} \mathrm{C}$ for $30 \mathrm{sec}$.

Western blot analysis. As previously described, total protein samples were isolated from the various treatment groups, separated on a $15 \%$ sodium dodecyl sulfate (SDS) polyacrylamide gel (50 $\mu \mathrm{g}$ protein/well), and transferred onto a nitrocellulose membrane (Hybond ${ }^{\mathrm{TM}}-\mathrm{C}$; Amersham Biosciences, Piscataway, NJ, USA). The membranes were 
blocked with $5 \%$ non-fat milk in Tris-buffered saline containing $0.1 \%$ Tween-20 at room temperature for $2 \mathrm{~h}$ and were then incubated with the following primary antibodies at $4^{\circ} \mathrm{C}$ overnight: rabbit anti-GABAAR pi primary antibody (1:1,000sc-25708; Santa Cruz Biotechnology, Inc., Santa Cruz, CA, USA), rabbit anti-phospho-p44/42 MAPK (Erk1/2) primary antibody $(1: 2,000,4370 \mathrm{~s})$, rabbit anti-p44/42 MAPK (ERK1/2) primary antibody (1:1,000, 4695s), rabbit anti-phospho-p38 MAPK primary antibody (1:1,000, 4511T), rabbit anti-p38 MAPK primary antibody $(1: 1,000,14451 \mathrm{~s})$, rabbit anti-phospho-JNK primary antibody $(1: 1,000,4668 \mathrm{~T})$, rabbit anti-JNK primary antibody $(1: 1,000,9252 \mathrm{~s})$, and goat anti-rabbit GAPDH primary antibody $(1: 1,000,2118 \mathrm{~S})$ (all from Cell Signaling Technology). Following incubation with the corresponding strain secondary antibodies (HRP-labeled goat anti-rabbit IgG $(\mathrm{H}+\mathrm{L})(1: 800, \mathrm{~A} 0208)$ for $60 \mathrm{~min}$ at room temperature, the membranes were subjected to enhanced chemiluminescence (BeyoECL Plus, P0018) (both from Beyotime Institute of Biotechnology, Haimen, China).

Immunofluorescence staining. The Tca8113 cells were cultured for $24 \mathrm{~h}$ and fixed in $4 \%$ paraformaldehyde solution for $15 \mathrm{~min}$ at room temperature. Following 3 washes in PBS, non-specific binding was blocked in PBS with 5\% BSA for $1 \mathrm{~h}$ at room temperature, and the samples were then incubated with rabbit anti-GABAAR pi primary antibody $(3.6 \mu \mathrm{g} / \mathrm{ml}$, ab26055; Abcam) at $4^{\circ} \mathrm{C}$ overnight. Following 3 washes in PBS, the cells were incubated with DyLight 594-conjugated goat anti-rabbit $\operatorname{IgG}(\mathrm{H}+\mathrm{L})$ (A23420; Abbkine, Redlands, CA, USA) at $37^{\circ} \mathrm{C}$ for $1 \mathrm{~h}$, and the nuclei were stained with DAPI staining solution (c1005; Beyotime Institute of Biotechnology) for $5 \mathrm{~min}$. Samples were viewed under a confocal laser scanning microscope (Leica, Heidelberg, Germany). The primary antibody was replaced with normal rabbit $\operatorname{IgG}(2 \mu \mathrm{g} / \mathrm{ml} \mathrm{IgG})$ instead of antiGABAAR pi primary antibody to serve as the negative controls.

CCK-8 cell proliferation assay. The effects of GABA, Muscimol and S106 on the proliferation of the Tca8113 cells were determined using the CCK- 8 reagent assay (Dojindo Molecular Technologies, Inc.). Briefly, $5 \times 10^{3}$ cells/well were grown in 96-well plates with the addition of GABA or GABA A type receptor agonist or antagonist and the treatment groups were as described above. Follwoing treatment for 24 and $48 \mathrm{~h}$, the appropriate amount of CCK-8 reagent $(1: 10, \mathrm{v} / \mathrm{v})$ was added to each well, and the cells were further incubated at $37^{\circ} \mathrm{C}$ for $1-4 \mathrm{~h}$ separately. The absorbance at a wavelength of $450 \mathrm{~nm}$ was measured using an enzyme-labeled instrument (ELx800; high-speed 8-channel filter-based absorbance; Chongqing Key Laboratory of Oral Diseases and Biomedical Sciences, Chongqing, China).

Flow cytometric analysis of cell cycle distribution and apoptosis. The effects of GABA, Muscimol and S106 on cell cycle distribution and the apoptosis of Tca8113 cells were measured by flow cytometric analysis. The treatment groups (cells treated with GABA or GABA A type receptor agonist or antagonist) were as described above. Cells were collected by trypsinization, washed twice in PBS at 24 and $48 \mathrm{~h}$ and an aliquot of the cells was then fixed in ice-cold $70 \%$ ethanol for a minimum overnight incubation, and other aliquots were re-suspended in PBS. The cell cycle distribution and apoptosis were analyzed using a flow cytometer (FACSVantage SE; BD Biosciences, San Jose, CA, USA).

Statistical analyses. Each experiment was performed at least 3 times. Analysis of variance (ANOVA) was performed and the results are presented as the means \pm standard deviation. Differences between the mean values of the individual groups were assessed by one-way ANOVA and Duncan's multiple range tests. The SPSS13.0 statistical software was used to perform all statistical analyses. Values of $\mathrm{P}<0.05$ were considered to indicate statistically significant differences and values of $\mathrm{P}<0.01$ were considered to indicate highly statistically significant differences.

\section{Results}

In this study, we analyzed GABRP expression in OSCC tissues using specific antibody (Fig. 1A-C). We found that GABRP was strongly located in the cytoplasm of poorly differentiated tumor tissue cells, particularly in the keratin pearl and also exhibited positive staining in well differentiated tissue cells in the cytoplasm. In benign fibroplastic tongue tissue, GABRP expression was observed in the cell cytoplasm with a lower expression level compared with the poorly differentiated OSCC tissues. These results raise the question of whether GABA expression is associated with OSCC.

RT-PCR and western blot analysis revealed that GABRP was expressed at the mRNA and protein level in the OSCC Tca8113 cell line (Fig. 1D and E). The results of immunofluorescence staining revealed that GABRP was located in the cytoplasm of Tca8113 cells (Fig. 2). Thus, the Tca8113 cell line was correctly used in this study to examine the function of GABA in vitro.

CCK-8 is a non-radioactive colorimetric assay used to measure cell proliferation or toxicity with a high sensitivity. The excessive proliferation of cells promotes tumor development. It has been reported that GABA expression is associated with tumor cell proliferation through its A receptor in neuronal or non-neuronal cancer (18). In this study, to measure the effects of GABA and the GABA A type receptor on Tca8113 cell proliferation, we treated the cells with GABA or Muscimol for 24 and $48 \mathrm{~h}$. We found that treatment with $1 \mu \mathrm{M}$ GABA or $5 \mu \mathrm{M}$ Muscimol promoted Tca8113 cell proliferation at 24 and $48 \mathrm{~h}$. To confirm the importance of the GABA A type receptor in the observed effects of GABA on Tca8113 cell proliferation, we used S106, which is an antagonist of the GABA A type receptor, to treat the Tca8113 cells in advance and then re-treated the cells with $1 \mu \mathrm{M}$ GABA. We found that the proliferative effects of $1 \mu \mathrm{M}$ GABA were blocked by treatment with $50 \mu \mathrm{M}$ S106 (Fig. 3; $\mathrm{P}<0.05$ ), suggesting that GABA promotes Tca8113 cell proliferation through its A type receptor.

The cell cycle is tightly regulated at two particular checkpoints, the G1-S and G2-M phases. Interestingly, we found that treatment with $1 \mu \mathrm{M}$ GABA or $5 \mu \mathrm{M}$ Muscimol significantly arrested the Tca8113 cells at the G2/M phase and shortened the G0/G1 phase at $48 \mathrm{~h}$. To confirm the importance of the GABA A type receptor in the observed effects of GABA on Tca8113 cell cycle distribution, we used S106, which is an antagonist of the GABA A type receptor, to treat the Tca8113 cell in advance and then re-treated the cells with $1 \mu \mathrm{M}$ GABA. We found that the effects of $1 \mu \mathrm{M}$ GABA on cycle distribution 


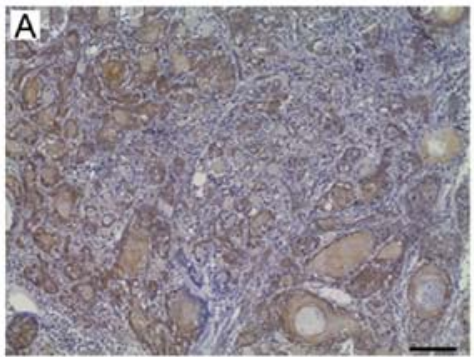

Poorly differentiated

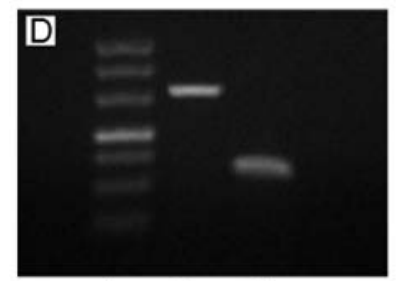

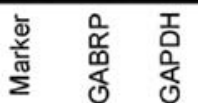

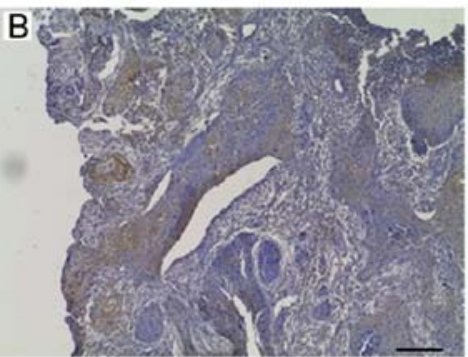

Well differentiated

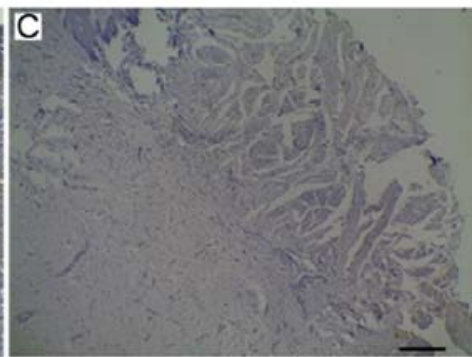

Fibroplasia
$\mathrm{E}$

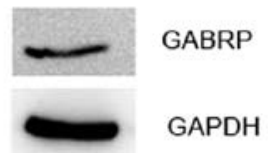

Figure 1. Immunostaining of GABA A type receptor pi subunit (GABRP) in oral squamous cell carcinoma (OSCC) tissues and Tca8113 cells. According to the standard of WHO (1971), the differentiation of cancer cells was divided into high (well differentiated), or medium and low (poorly differentiated) levels. (A-C) Immunochemical determination of GABRP expression in the tumor area of (A) poorly differentiated and (B) well differentiated tongue squamous cell carcinoma tissue and in (C) fibroplasia tissue. Scale bar, $75 \mu \mathrm{m}$. GABRP expression was stronger in the cytoplasm of tumor cells in poorly differentiated tongue squamous cell carcinoma tissue, particularly in the keratin pearl and mild staining was observed in fibroplasia tissue. (D) Semi-quantitative RT-PCR analysis of GABRP mRNA expression in Tca8113 cells. (E) Western blot analysis of GABRP protein expression in Tca8113 cells.
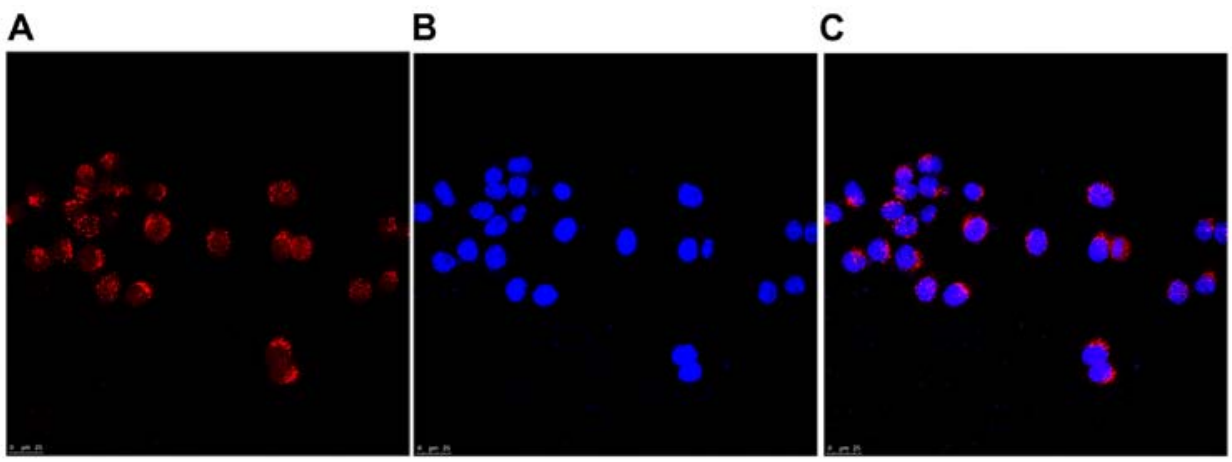

Figure 2. Immunofluorescence staining of GABA A type receptor pi subunit (GABRP) in Tca8113 cells. (A) Red signals represent GABRP staining and (B) blue signals indicate nuclear staining. (C) Merged image of parts A and B. Scale bar, $25 \mu \mathrm{m}$.

on the Tca8113 cells were blocked by treatment with $50 \mu \mathrm{M}$ S106 (Fig. 4; $\mathrm{P}<0.05$ ), suggesting that GABA disrupts the Tca8113 cell cycle distribution through its A type receptor.

The apoptotic rate of Tca8113 cells was notably decreased following the addition of 1 or $5 \mu \mathrm{M}$ Muscimol to the culture medium. To determine the importance of the GABA A type receptor in the observed effects of GABA on Tca8113 cell apoptosis, we used S106, which is an antagonist of the GABA A type receptor, to treat the Tca 8113 cells in advance and then re-treated the cells with $1 \mu \mathrm{M}$ GABA. We found that the effects of $1 \mu \mathrm{M}$ GABA on the apoptosis of Tca8113 cells were blocked by treatment with $50 \mu \mathrm{M}$ S106 (Fig. 5; P<0.05), suggesting that GABA inhibits Tca8113 cell apoptosis through its A type receptor.

The MAPK signal transduction pathways are evolutionarily conserved and are related to cell growth or survival (20). Thus, in this study, the expression and activation of MAPKs were examined by western blot analysis using specific antibodies. To examine the activity of ERK, p38 and JNK, phosphorylated ERK1/2 (p-ERK1/2), phosphorylated p38 (p-p38) and phosphorylated JNK1/2 (p-JNK1/2), specific antibodies were used as described in the Materials and methods. As a control, total ERK1/2, p38 and JNK1/2 protein was analyzed. GAPDH was used as a loading control. The results of western blot analysis revealed that treatment with $1 \mu \mathrm{M}$ GABA or $5 \mu \mathrm{M}$ Muscimol increased the levels of phosphorylated p38, whereas it decreased those of JNK1/2 compared with the blank (untreated) control. However, to determine the importance of the GABA A type receptor in the observed effects of GABA on the levels of phosphorylated kinases, we used S106, which is an antagonist of the GABA A type receptor, to treat the cells in advance and then re-treated the cells with $1 \mu \mathrm{M}$ GABA. We found that the effects of $1 \mu \mathrm{M}$ GABA on the levels of phosphorylated p38 and 
A
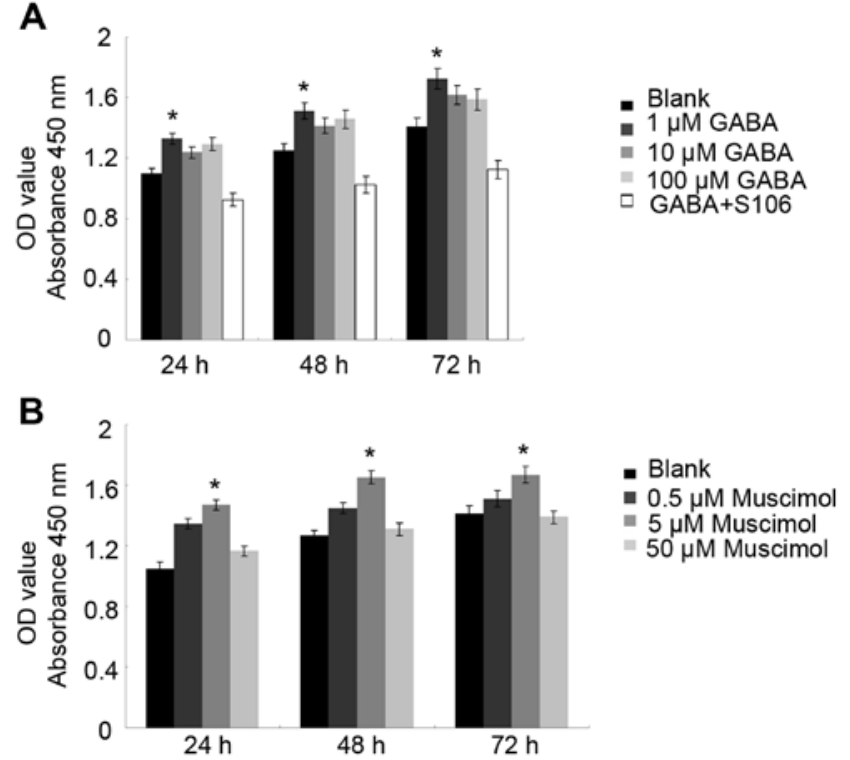

Figure 3. (A) Effects of gamma-aminobutyric acid (GABA) on the proliferation of Tca8113 cells. (B) Effects of GABA A type receptor agonist (Muscimol) on the proliferation of Tca8113 cells. Cells were treated with 1,10 or $100 \mu \mathrm{M} \mathrm{GABA}$ and $0.5,5$, or $50 \mu \mathrm{M}$ Muscimol separately and were then analyzed by CCK- 8 assay, after which the absorbance was measured at a wavelength of $450 \mathrm{~nm}$ using an enzyme-labeled instrument. Treatment with both $1 \mu \mathrm{M}$ GABA and $5 \mu \mathrm{M}$ Muscimol increased the absorbance values at 24 and $48 \mathrm{~h}$ compared with the blank control (data are the means \pm SD of 3 independent experiments). ${ }^{*} \mathrm{P}<0.05$, as compared with the blank control. These result revealed that both $1 \mu \mathrm{M}$ GABA and $5 \mu \mathrm{M}$ Muscimol stimulated Tca8113 cell proliferation. Treatment with $50 \mu \mathrm{M}$ GABA A type receptor antagonist (S106) blocked the proliferative effects of $1 \mu \mathrm{M}$ GABA at 24,48 and $72 \mathrm{~h}$ which indicated that GABA stimulated Tca8113 cell proliferation by through itsA type receptor.

JNK1/2 were blocked by treatmetn with $50 \mu \mathrm{M}$ S106 (Fig. 6; $\mathrm{P}<0.05$ ), suggesting that GABA interferes with the activation of MAPKs in Tca8113 cells through its A type receptor.

\section{Discussion}

OSCC of the tongue is the sixth most common type of human cancer worldwide, and $>90 \%$ of oral malignancies are SCCs (21). In this study, we found that GABRP was expressed in benign tongue tissue samples, with a lower expression level compared with the poorly differentiated OSCC tissue samples. Previous studies have demonstrated that GABA promotes the functions of cell proliferation and inhibits apoptosis through its A type receptor in peripheral non-neuronal tissues $(22,23)$. These results prompted us to investigate the association between GABA and the proliferation and apoptosis of OSCC cells.

Among its three receptors (A, B and C), GABA A type receptor has been extensively investigated with regard to its complex functions. Approximately 21 types of subunits have been found in the GABA A type receptor and the functional GABA A type receptor has 5 subunits assembled into 5 dimers. The $\alpha \beta \gamma$ subunits widely exist in a variety of 5 dimers. The pi subunit which is abundant in various peripheral tissues plays an important role in the functions of GABA A type receptor $(24,25)$. Moreover, it has been demonstrated that the expression of GABA is significantly increased in neoplastic tissues, such as in colorectal carcinoma, hepatocellularcarcinoma and gastric cancer, as compared with normal tissues $(18,26)$.
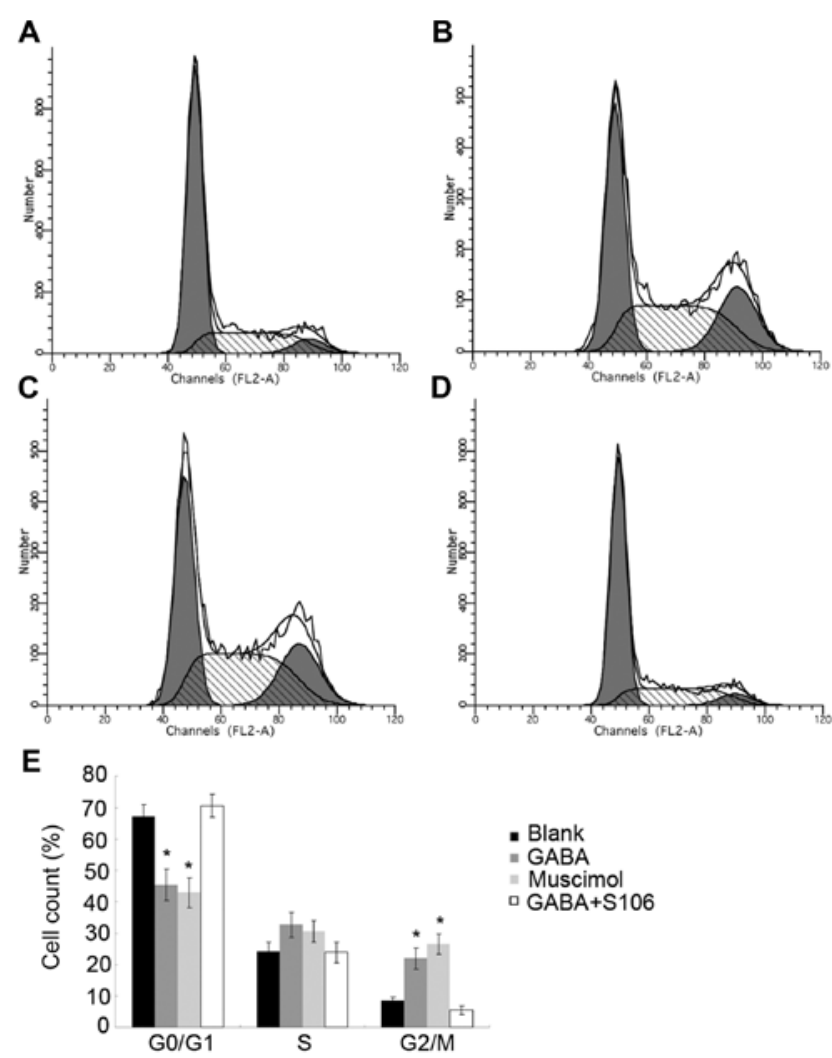

Figure 4. Effects of gamma-aminobutyric acid (GABA) and the GABA A type receptor on cell cycle distribution in Tca8113 cells. Tca8113 cells treated with 1,10 or $100 \mu \mathrm{M}$ GABA and $0.5,5$ or $50 \mu \mathrm{M}$ Muscimol separately were analyzed by flow cytometry to determine the cell cycle distribution. (A-D) At $48 \mathrm{~h}$, compared with the (A) control group, the (B) $1 \mu \mathrm{M}$ GABA group and the (C) $5 \mu \mathrm{M}$ Muscimol group displayed an increased percentage of cells in $\mathrm{G} 2 / \mathrm{M}$ phase and a decreased percentage of cells in the G0/G1 phase, whereas treatment with (D) $50 \mu \mathrm{M} \mathrm{S} 106$ reversed the effects of treatment with $1 \mu \mathrm{M}$ GABA. (E) Statistical analysis of the cell cycle distribution in various groups (data are the means $\pm \mathrm{SE}$ of 3 independent experiments). ${ }^{*} \mathrm{P}<0.05$, as compared with the blank control. These results revealed that treatment with $1 \mu \mathrm{M}$ GABA or $5 \mu \mathrm{M}$ Muscimol significantly arrested the Tca8113 cells in the $\mathrm{G} 2 / \mathrm{M}$ phase and shortened the G0/G1 phase at $48 \mathrm{~h}$. Treatment with $50 \mu \mathrm{M}$ GABA A type receptor antagonist (S106 (blocked the effects of $1 \mu \mathrm{M}$ GABA at $48 \mathrm{~h}$, which indicated that GABA disrupted the Tca8113 cell cycle distribution through its A type receptor.

Therefore, we have reason to speculate that GABA plays a role in on tongue cancer cell proliferation. CCK-8 assay revealed that treatment with $1 \mu \mathrm{M}$ GABA or $5 \mu \mathrm{M}$ Muscimol promoted Tca 8113 cell proliferation and arrested the cells in the G2/M phase effectively. Flow cytometry was also used to determine whether GABA affects cell apoptosis. We found that the apoptosis of the Tca8113 cells was inhibited by treatment with $1 \mu \mathrm{M}$ GABA or $5 \mu \mathrm{M}$ Muscimol. To confirm the role of the GABA A type receptor in the observed effects of GABA on Tca8113 cell apoptosis, we used S106, which is an antagonist of the GABA A type receptor, to treat the Tca8113 cells in advance and then re-treated the cells with $1 \mu \mathrm{M}$ GABA. We found that the anti-apoptotic effects of $1 \mu \mathrm{M}$ GABA were blocked by treatment with $50 \mu \mathrm{M}$ S106, suggesting that GABA inhibits Tca8113 cell apoptosis through its A type receptor. The examination of the proliferation and apoptosis of Tca8113 cells confirmed that a lower concentration of GABA and a middle concentration of Muscimol group promoted cell proliferation effectively but at present, we are unable to explain this phenomenon. 
A

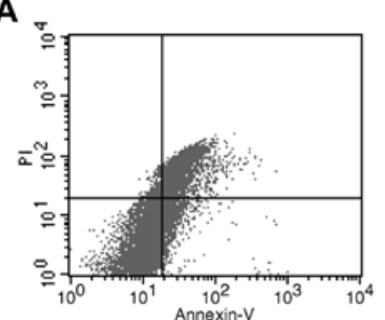

C
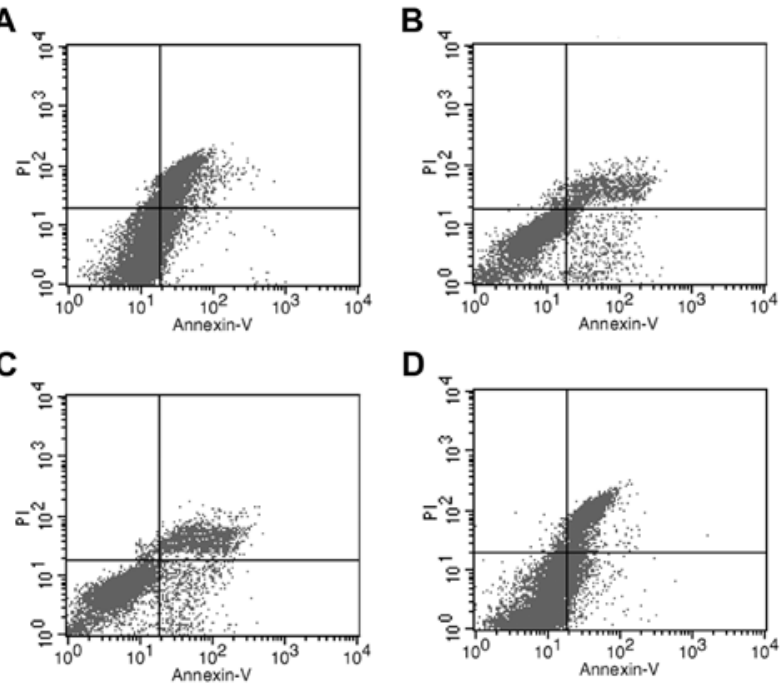

D

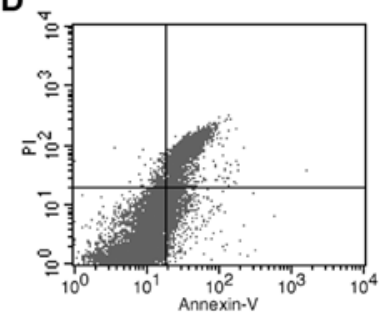

E

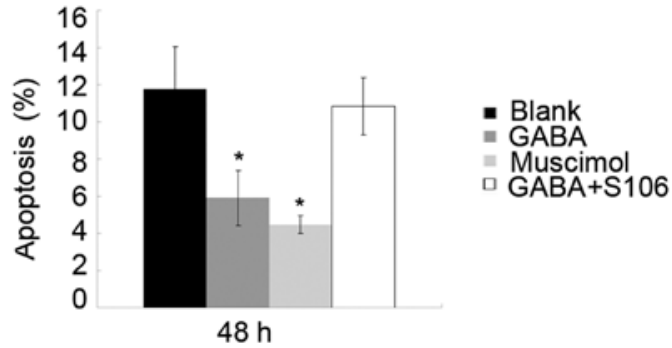

Figure 5. Effects of gamma-aminobutyric acid (GABA) and the GABA A type receptor on the apoptosis of Tca8113 cells. Flow cytometric analysis of apoptosis of Tca8113 cells treated with 1,10 or $100 \mu \mathrm{M}$ GABA and $0.5,5$ or $50 \mu \mathrm{M}$ Muscimol separately. (A-D) At $48 \mathrm{~h}$, the apoptotic rate of the cells treated with (B) $1 \mu \mathrm{M}$ GABA, (C) $5 \mu \mathrm{M}$ Muscimol was decreased compared with (A) the blank control group. (D) Treatment with $50 \mu \mathrm{M}$ GABA A type receptor antagonist (S106) blocked the apoptotic effects of treatment with $1 \mu \mathrm{M}$ GABA on apoptosis. (E) Statistical analysis of the cell apoptotic rate in the various groups (data are the means \pm SD of 3 independent experiments). ${ }^{*} \mathrm{P}<0.05$, as compared with the blank control. Treatment with $50 \mu \mathrm{M} \mathrm{GABA}$ A type receptor antagonist (S106) blocked the effects of $1 \mu \mathrm{M}$ GABA at $48 \mathrm{~h}$, which indicated that GABA inhibited Tca8113 cell apoptosis through its A type receptor.

The MAPK signal transduction pathways are stimulated by the binding of mitogens, hormones, or neurotransmitters to receptor tyrosine kinases, and the transduction of exogenous signals is achieved through sequential phosphorylation, regulating gene expression and cell proliferation, differentiation and apoptosis. The kinases, MAPK kinase kinases (MAPKKKs), can be phosphorylated by mall G-proteins leading to double phosphorylation and activation of downstream MAPKKs (27,28). A recent study indicated that MAPK activation is an essential function of many anticancer drugs which induce tumor cell apoptosis (20). ERK1 and ERK2 are two key transducers of proliferation, differentiation and survival signals which exist in almost all tissues, mainly affecting the cells by G1-to S-phase progression. p38 MAPK activitation induces cell proliferation in the majority of cancers, arresting cells at the G2/M phase. There are some interactions between the JNK isoforms and p38 MAPK (27). It has been shown that JNK1 and JNK2 activation, and p38 MAPK inhibition are involved in cisplatin-induced cell death (28). OSCC is one of the 10 most common human malignant tumors, accouting for $>80 \%$ of oral and maxillofacial malignant tumors $(29,30)$. Various factors, such as growth factors, protein kinases and infammatory
A

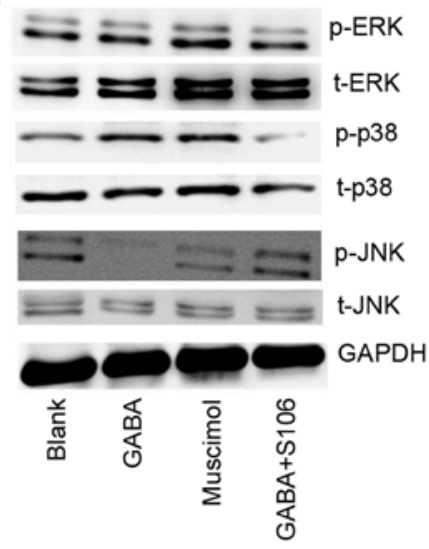

B

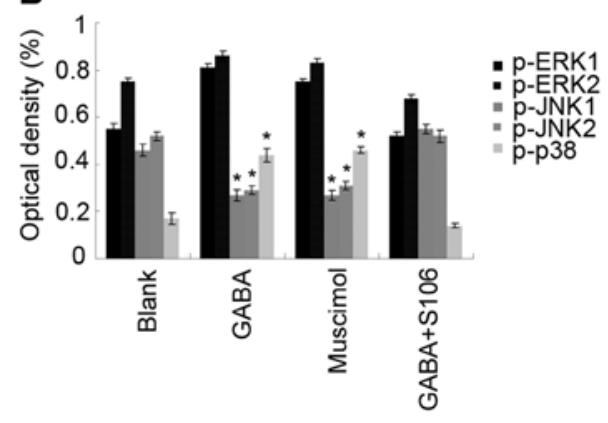

Figure 6. Effect of gamma-aminobutyric acid (GABA) and the GABA A type receptor on mitogen-activated protein kinase (MAPK) activation by western blot analysis. As a control, total ERK, p38 and JNK protein was analyzed. GAPDH was used as a loading control. (A) Treatment with $1 \mu \mathrm{M}$ GABA and $5 \mu \mathrm{M}$ Muscimol increased the phosphorylation level of $\mathrm{p} 38$ and decreased the JNK1/2 phosphorylation level. The effect of $1 \mu \mathrm{M}$ GABA on the phosphorylation level of p38 was blocked by treatment with $50 \mu \mathrm{M}$ GABA A type receptor antagonist (S106). There were no changes in the total protein levels of ERK, p38 and JNK. (B) Statistical analysis of the phosphorylation level of ERK, p38 and JNK gray value ratio in the various groups (data are the means \pm SD of 3 independent experiments). ${ }^{*} \mathrm{P}<0.05$.

mediators contribute to tumor progression and the process may involve crosstalk with different signaling pathways (31-35). Theocharis et al reported ERK expression and activation in 47 mobile tongue SCC tissue samples and associations with clinicopathological parameters and patient survival (36). In this study, we found that treatment with GABA or Muscimol activates p38 MAPK, but inhibits JNK MAPK. Our results demonstrated that treatment with GABA or Muscimol inhibited the apoptosis of Tca8113 cells, promoted proliferation and arrested the cells in the G2/M phase effectively, as shown by flow cytometry. Our results are consistent with those of studies on the role of the MAPK signaling pathway in tumors (37).

As the major inhibitory neurotransmitter in the adult mammalian CNS, drugs acting upon receptors of GABA and GABA 'mimetics' (e.g., gabapentin) are used to treat patients with cancer. There is evidence indicating that the deregulation of the GABA system can cause or contribute to the onset of cancers, such as pancreatic ductal adenocarcinoma and gastric carcinoma (19). However, the deregulation of the GABA system has potential carcinogenic effects remains unclear. However, the findings of our study suggest the necessity to proceed with caution when using GABAergic drugs and GABA 'mimetics' in patients with tongue cancer. 
In conclusion, our study provide some lines of evidence that GABA is actively involved in promoting OSCC Tca8113 cell proliferation and suppressing apoptosis through GABA A type receptors via the activation of p38 MAPK, but the inhibition of the JNK MAPK signaling pathways. This may confirm our concerns regarding the use of GABAergic drugs and GABA 'mimetics' in patients with tongue cancer.

\section{Acknowledgements}

This study was supported by grants from the National Natural Science Foundation of China (no. 31301021), Program for Innovation Team Building at Institutions of Higher Education in Chongqing in 2013 and Chongqing Municipal Key Laboratory of Oral Biomedical Engineering of Higher Education.

\section{References}

1. Blot WJ, McLaughlin JK, Winn DM, Austin DF, Greenberg RS Preston-Martin S, Bernstein L, Schoenberg JB, Stemhagen A and Fraumeni JF Jr: Smoking and drinking in relation to oral and pharyngeal cancer. Cancer Res 48: 3282-3287, 1988.

2. Rentoft M, Coates PJ, Loljung L, Wilms T, Laurell G and Nylander K: Expression of CXCL10 is associated with response to radiotherapy and overall survival in squamous cell carcinoma of the tongue. Tumour Biol 35: 4191-4198, 2014.

3. Fu X and Feng Y: QKI-5 suppresses cyclin D1 expression and proliferation of oral squamous cell carcinoma cells via MAPK signalling pathway. Int J Oral Maxillofac Surg 44: 562-7, 2014. doi: 10.1016/j.ijom.2014.10.001.

4. Ntziachristos P, Lim JS, Sage J and Aifantis I: From fly wings to targeted cancer therapies: a centennial for notch signaling. Cancer Cell 25: 318-334, 2014.

5. Kamran MZ, Patil P and Gude RP: Role of STAT3 in cancer metastasis and translational advances. Biomed Res Int 2013: 421821, 2013

6. Fujii R, Imanishi Y, Shibata K, Sakai N, Sakamoto K, Shigetomi S, Habu N, Otsuka K, Sato Y, Watanabe Y, et al: Restoration of E-cadherin expression by selective Cox-2 inhibition and the clinical relevance of the epithelial-to-mesenchymal transition in head and neck squamous cell carcinoma. J Exp Clin Cancer Res 33: 40-52, 2014.

7. Dalianis T: Human papillomavirus and oropharyngeal cancer, the epidemics, and significance of additional clinical biomarkers for prediction of response to therapy (Review). Int J Oncol 44: 1799-1805, 2014

8. Nagata M, Wada K, Nakajima A, Nakajima N, Kusayama M, Masuda T, Iida S, Okura M, Kogo M and Kamisaki Y: Role of myeloid cell leukemia-1 in cell growth of squamous cell carcinoma. J Pharmacol Sci 110: 344-353, 2009.

9. Watanabe M, Maemura K, Kanbara K, Tamayama $\mathrm{T}$ and Hayasaki H: GABA and GABA receptors in the central nervous system and other organs. Int Rev Cytol 213: 1-47, 2002.

10. Irwin RP and Allen CN: GABAergic signaling induces divergent neuronal $\mathrm{Ca}^{2+}$ responses in the suprachiasmatic nucleus network. Eur J Neurosci 30: 1462-1475, 2009.

11. Al-Wadei HA, Plummer HK III and Schuller HM: Nicotine stimulates pancreatic cancer xenografts by systemic increase in stress neurotransmitters and suppression of the inhibitory neurotransmitter gamma-aminobutyric acid. Carcinogenesis 30: 506-511, 2009.

12. Deng Y, Wang W, Yu P, Xi Z, Xu L, Li X and He N: Comparison of taurine, GABA, Glu, and Asp as scavengers of malondialdehyde in vitro and in vivo. Nanoscale Res Lett 8: 190, 2013.

13. Ortega A: A new role for GABA: inhibition of tumor cell migration. Trends Pharmacol Sci 24: 151-154, 2003.

14. Macdonald RL and Olsen RW: GABAA receptor channels. Annu Rev Neurosci 17: 569-602, 1994.

15. Fujii E and Mellon SH: Regulation of uterine gamma-aminobutyric acid(A) receptor subunit expression throughout pregnancy. Endocrinology 142: 1770-1777, 2001.

16. Follesa P, Serra M, Cagetti E, Pisu MG, Porta S, Floris S, Massa F, Sanna E and Biggio G: Allopregnanolone synthesis in cerebellar granule cells: roles in regulation of GABA(A) receptor expression and function during progesterone treatment and withdrawal. Mol Pharmacol 57: 1262-1270, 2000.
17. Majewska MD and Vaupel DB: Steroid control of uterine motility via gamma-aminobutyric acidA receptors in the rabbit: a novel mechanism? J Endocrinol 131: 427-434, 1991.

18. Maemura K, Shiraishi N, Sakagami K, Kawakami K, Inoue T, Murano M, Watanabe M and Otsuki Y: Proliferative effects of gamma-aminobutyric acid on the gastric cancer cell line are associated with extracellular signal-regulated kinase 1/2 activation. J Gastroenterol Hepatol 24: 688-696, 2009.

19. Lee SK, Dawson J, Lee JA, Osman G, Levitin MO, Guzel RM and Djamgoz MB: Management of cancer pain: wider implications of orthodox analgesics. Int J Gen Med 7: 49-58, 2014.

20. Yuan L, Wang J, Xiao H, Wu W, Wang Y and Liu X: MAPK signaling pathways regulate mitochondrial-mediated apoptosis induced by isoorientin in human hepatoblastoma cancer cells. Food Chem Toxicol 53: 62-68, 2013.

21. Ferrari D, Codecà C, Fiore J, Moneghini L, Bosari S and Foa P: Biomolecular markers in cancer of the tongue. 2009: 412908, 2009.

22. Tamayama T, Maemura K, Kanbara K, Hayasaki H, Yabumoto Y, Yuasa $M$ and Watanabe $M$ : Expression of GABA(A) and GABA(B) receptors in rat growth plate chondrocytes: activation of the GABA receptors promotes proliferation of mouse chondrogenic ATDC5 cells. Mol Cell Biochem 273: 117-126, 2005.

23. Takehara A, Hosokawa M, Eguchi H, Ohigashi H, Ishikawa O, Nakamura $Y$ and Nakagawa H: Gamma-aminobutyric acid (GABA) stimulates pancreatic cancer growth through overexpressing GABAA receptor pi subunit. Cancer Res 67: 9704-9712, 2007.

24. Neelands TR and Macdonald RL: Incorporation of the pi subunit into functional gamma-aminobutyric Acid(A) receptors. Mol Pharmacol 56: 598-610, 1999.

25. Hedblom E and Kirkness EF: A novel class of GABAA receptor subunit in tissues of the reproductive system. J Biol Chem 272: 15346-15350, 1997.

26. Zhang M, Gong Y, Assy N and Minuk GY: Increased GABAergic activity inhibits alpha-fetoprotein mRNA expression and the proliferative activity of the HepG2 human hepatocellular carcinoma cell line. J Hepatol 32: 85-91, 2000.

27. Lei YY, Wang WJ, Mei JH and Wang CL: Mitogen-activated protein kinase signal transduction in solid tumors. Asian Pac J Cancer Prev 15: 8539-8548, 2014.

28. Cargnello M and Roux PP: Activation and function of the MAPKs and their substrates, the MAPK-activated protein kinases. Microbiol Mol Biol Rev 75: 50-83, 2011.

29. Warnakulasuriya S: Global epidemiology of oral and oropharyngeal cancer. Oral Oncol 45: 309-316, 2009.

30. Bitu CC, Kauppila JH, Bufalino A, Nurmenniemi S, Teppo S, Keinänen M, Vilen ST, Lehenkari P, Nyberg P, Coletta RD and Salo T: Cathepsin $\mathrm{K}$ is present in invasive oral tongue squamous cell carcinoma in vivo and in vitro. PLoS One 8: e70925, 2013.

31. Han X, Han Y, Jiao H and Jie Y: $14-3-3$ ל regulates immune response through Stat 3 signaling in oral squamous cell carcinoma. Mol Cells 38: 112-21, 2014. doi: 10.14348/molcells.2015.2101.

32. Yan M, Xu Q, Zhang P, Zhou XJ, Zhang ZY and Chen WT: Correlation of NF-kappaB signal pathway with tumor metastasis of human head and neck squamous cell carcinoma. BMC Cancer 10: 437-443, 2010.

33. Nariai Y, Mishima K, Yoshimura Y and Sekine J: FAP-1 and $\mathrm{NF}-\kappa \mathrm{B}$ expressions in oral squamous cell carcinoma as potential markers for chemo-radio sensitivity and prognosis. Int J Oral Maxillofac Surg 40: 419-426, 2011.

34. Chen IC, Chiang WF, Huang HH, Chen PF, Shen YY and Chiang HC: Role of SIRT1 in regulation of epithelial-to-mesenchymal transition in oral squamous cell carcinoma metastasis. Mol Cancer 13: 254-267, 2014.

35. Ekshyyan O, Moore-Medlin TN, Raley MC, Sonavane K, Rong X, Brodt MA, Abreo F, Alexander JS and Nathan CA: Anti-lymphangiogenic properties of mTOR inhibitors in head and neck squamous cell carcinoma experimental models. BMC Cancer 13: 320-329, 2013.

36. Theocharis S, Kotta-Loizou I, Klijanienko J, Giaginis C, Alexandrou P, Dana E, Rodriguez J, Patsouris E and Sastre-Garau X: Extracellular signal-regulated kinase (ERK) expression and activation in mobile tongue squamous cell carcinoma: associations with clinicopathological parameters and patients survival. Tumour Biol 35: 6455-6465, 2014.

37. Li Y, Lu X, Qi H, Li X, Xiao X and Gao J: Ursolic acid induces apoptosis through mitochondrial intrinsic pathway and suppression of ERK1/2 MAPK in HeLa cells. J Pharmacol Sci 125: 202-210, 2014. 